\title{
Exposure to oral bisphosphonates and risk of cancer
}

\author{
Chris R. Cardwell ${ }^{1}$, Christian C. Abnet ${ }^{2}$, Philip Veal ${ }^{1}$, Carmel. M Hughes ${ }^{3}$, Marie M. \\ Cantwell $^{1}$, and Liam J. Murray ${ }^{1}$
}

${ }^{1}$ Centre for Public Health, Queen's University Belfast, United Kingdom ${ }^{2}$ Nutritional Epidemiology Branch, Division of Cancer Epidemiology and Genetics, National Cancer Institute, National Institutes of Health, Rockville, Maryland ${ }^{3}$ School of Pharmacy, Queen's University Belfast, United Kingdom

\begin{abstract}
Recently oral bisphosphonate use has increased markedly in the United States and elsewhere. Little is known about cancer risks associated with these drugs. A few studies have observed associations between bisphosphonates and the risk of breast, colorectal and esophageal cancer. However, the risk of all cancer and the risk of other cancers have not been investigated. In this study we examined the risk of all cancer and site specific cancers in individuals taking bisphosphonates. Data were extracted from the UK General Practice Research Database to compare site-specific cancer incidence in a cohort of oral bisphosphonate users and a control cohort. Hazard ratios were calculated using Cox regression modelling. The bisphosphonate and control cohort contained 41,826 participants (mean age 70, 81\% female). Overall, the bisphosphonate cohort compared with the control cohort had a reduced risk of all cancer after any bisphosphonate usage ( $\mathrm{HR}=0.87,95 \% \mathrm{CI} 0.82,0.92)$. In the bisphosphonate cohort, compared with the control cohort, there was no evidence of a difference in the risk of lung ( $\mathrm{HR}=1.03,95 \%$ CI $0.88,1.20)$ or prostate cancer $(\mathrm{HR}=0.86,95 \% \mathrm{CI} 0.67,1.09)$ but breast $(\mathrm{HR}=0.71,95 \% \mathrm{CI}$ $0.62,0.81)$ and colorectal cancer ( $\mathrm{HR}=0.74,95 \% \mathrm{CI}, 0.60-0.91)$ were both reduced. Our findings indicate that bisphosphonates do not appear to increase cancer risk. Although reductions in breast and colorectal cancer incidence were observed in bisphosphonate users it is unclear, particularly for breast cancer, to what extent confounding by low bone density may explain the association.
\end{abstract}

\section{Keywords}

cancer; risk; bisphosphonates; cohort; epidemiology

\section{Introduction}

Bisphosphonates inhibit osteoclast-mediated bone resorption and are established in the prevention or treatment of osteoporosis. Bisphosphonate use has increased dramatically in recent years in Western populations (1-3) but the long term cancer risks associated with these drugs are unknown. Preclinical data suggest that bisphosphonates may exert antitumor activity through mechanisms including inhibition of angiogenesis and cellular proliferation, cell-cycle arrest, induction of apoptosis in cancer cell lines, prevention of tumour cell adhesion and extravasation, and activation of immune cells with anticancer activity. (4-7) Clinical trials also support an anti-neoplastic role for bisphosphonates. Some, $(8 ; 9)$ but not all,(10) trials of early generation oral bisphosphonate clodronate as adjuvant therapy in

Corresponding Author: Chris R. Cardwell, PhD, Centre for Public Health, Queen's University Belfast, Grosvenor Rd, Belfast BT12 6BJ, United Kingdom, Phone: +44 (0) 289063 2620, Fax: +44 (0) 289023 5900, c.cardwell@ qub.ac.uk. 
breast cancer patients showed improvements in overall survival and bone metastasis free survival. Trials of zoledronate in endocrine-responsive breast cancer patients have also shown increased disease free survival, decreased loco-regional recurrences and contralateral breast cancer.(11-13). Few epidemiological studies investigating the risk of cancer in bisphosphonate users have been conducted. Three studies (14-16) have investigated bisphosphonate use and breast cancer risk, two studies $(17 ; 18)$ have investigated bisphosphonate use and colorectal cancer risk and two studies $(17 ; 19)$ including an earlier report from this cohort (19), have investigated bisphosphonate use and esophageal cancer risk. However, there have not been any studies which have investigated the entire cancer burden in bisphosphonate users or studies which have investigated the risk of cancer at other sites (including lung, prostate, ovarian etc.) in bisphosphonate users. The main aim of this study was to investigate the risk of all cancer and cancer by site in a cohort of bisphosphonate users. These analyses will better allow the risks and benefits of bisphosphonate use on all cancer incidence to be determined. Also, the investigation of previously unstudied cancer sites may identify additional cancers which may be influenced by bisphosphonate usage.

\section{Materials and Methods}

The study cohorts have previously been described in detail.(19) Cohorts were identified within UKGPRD, the world's largest computerized database of anonymized longitudinal patient records including approximately $6 \%$ of the UK population. The high quality of GPRD prescription and diagnosis information has been documented.(20) Ethical approval for all observational research using GPRD data has been obtained from a multicentre research ethics committee.

We established an initial bisphosphonate cohort of all patients receiving a prescription for oral bisphosphonates (from January 1, 1996 to December 31, 2006). The date of first oral bisphosphonate prescription was taken as the index date. Participants were excluded if they were younger than 40 years on their initial index date or if they had a prior cancer diagnosis (excluding non-melanoma skin cancer) recorded within GPRD. In sequential order (by date of first bisphosphonate prescription), each bisphosphonate user was matched to a single control (who was allocated their index date) randomly selected from individuals of the same sex, year of birth, and general practice, regardless of bisphosphonate use (to avoid removing patients from the cohort who received bisphosphonates for cancer-related osteoporosis/ metastasis, thereby artificially reducing the risk of cancer in the control cohort). Therefore, some control participants used bisphosphonates, but once selected as control participants, they were excluded from the bisphosphonate cohort. All bisphosphonate and control cohort members had to have at least 3 years of data within GPRD prior to the index date.

Cancers were identified from Read/Oxford Medical Information System codes in patients' clinical files. All cancer codes were examined by a physician/epidemiologist (L.J.M) blinded to whether the patient was in the bisphosphonate or control cohort. Cancer codes were categorised into: breast, lung, colorectal, prostate, ovarian, endometrial, unspecified female reproductive tract, lymphoma/leukaemia, gastro-esophageal, bladder, malignant melanoma, myeloma, pancreas, and other sites or site unclear. Date of first cancer code was considered the diagnosis date. Cancer incidence was compared in the bisphosphonate and control cohorts prior to the date on which data were downloaded from each general practice (more than $90 \%$ by August 1, 2008).

\section{Classification of Bisphosphonate Exposure}

All prescriptions for oral bisphosphonates were identified. Data on the preparations prescribed, the date of prescription, and the number of packs/tablets prescribed were 
extracted and converted to defined daily doses (DDDs), which are the assumed average maintenance dose per day of a drug used for its main indication in adults, which for oral bisphosphonates is the prevention or treatment of osteoporosis.

\section{Data Extraction Relating to Potential Confounders}

Data on smoking, alcohol consumption, and body mass index (BMI) in the 3-year period before the index date were extracted, and the record closest to the index date was used. Subjects with a recorded code for osteoporosis or osteopenia at any time, or who had a code for any fracture recorded in the 3-year period prior to the index date, were identified. Subjects who had received five or more prescriptions for hormone replacement therapy (HRT) or oral steroids or 10 or more prescriptions for non steroidal anti-inflammatory drugs (NSAIDs) in the 3-year period prior to the index date were identified, as were subjects who received one or more prescriptions for calcium and/or vitamin D supplements in the 6-month period after the index date. Smoking, alcohol, BMI and HRT use were considered confounders as they are associated with both low bone density and cancer risk. Receipt of NSAIDs, calcium and/or vitamin D are associated with reduced cancer risk and are potential confounders.(21-24)

\section{Statistical Analysis}

The ascertainment of cancer within GPRD was estimated by calculating the expected number of cancers in the control cohort using the person-years of follow up in the cohort and the age and sex specific incidence rates from England in 2005 (http://

www.statistics.gov.uk/default.asp). A standardized incidence ratio (SIR) was then calculated and exact methods used to calculate $95 \%$ confidence intervals (CIs).

Survival analysis was conducted separately for each cancer site/group of sites on the time from index date to the specific cancer diagnosis of interest or to the date of censoring. Participants were censored at the first of the following outcomes: date of other cancer diagnosis (except for the all cancer diagnosis analysis), date of death, date of leaving general practice, or date of last data download from general practice by GPRD. The first 6 months of follow-up was removed for every participant, because cancer incidence in this period is unlikely to be attributable to bisphosphonate usage. Kaplan-Meier curves were plotted to investigate time to cancer diagnosis in the two cohorts and to check the assumption of proportional hazards. The Cox proportional hazards model was used to calculate all hazard ratios (HRs) and 95\% CIs and to adjust for potential confounding variables. The assumption of proportional hazards was checked by inspection of survival curves and within the proportional hazards model by tests of the interaction between the co-variate with time. Confounders with missing data were included using a missing data category, and a complete case analysis was also conducted (not shown, as estimates were little altered). Separate analyses were conducted comparing the risk of the common cancers in the bisphosphonate and control cohort after adjustment for BMI only, alcohol consumption only and smoking status only (not shown, as estimates were little altered), allowing larger numbers of individuals to contribute as these variables were missing for the greatest proportion of individuals. Analyses were repeated for users of nitrogen-containing bisphosphonates and alendronate.

To investigate dose response, separate analyses were conducted, for breast and colorectal cancer, including only follow-up time after the bisphosphonate user had received 1, 2, 3 and 4 years DDDs (follow-up from the same date for matched controls). In order to explore potential confounding by indication, subgroup analyses (25) were conducted for breast and colorectal cancer including only pairs of bisphosphonate users and controls in which the control was diagnosed with osteoporosis/osteopenia prior to the index date or a fracture in 
the 3-year period prior to the index date. Unpaired analyses (with adjustment for age and sex) that included only members of the bisphosphonate and control cohorts with a prior diagnosis of osteoporosis/osteopenia or fracture were also conducted. All conducted hypothesis tests were two-sided. All statistical analyses were conducted using STATA version 9 (StataCorp, College Station, Texas).

\section{Results}

Data were extracted from GPRD for 46,036 oral bisphosphonate users and 46,036 matched controls. During follow-up 5,956 cancers were recorded in the bisphosphonate and control cohorts. To estimate completeness of ascertainment of cancers in the GPRD, SIRs for cancers in the control cohort compared with age and sex specific incidence rates from England in 2005 are shown in Table 1. The SIR for all cancers in the control cohort was slightly elevated (SIR=1.09, 95\% CI 1.05, 1.13). SIRs for most cancers were similar to those expected from national rates but rates of bladder cancer ( $\mathrm{SIR}=1.45)$, myeloma $(\mathrm{SIR}=1.37)$ and malignant melanoma $(\mathrm{SIR}=1.47)$ were significantly higher than expected whilst the pancreas cancer rate $(\mathrm{SIR}=0.75)$ was significantly lower.

In bisphosphonate cohort 41,826 participants had at least 6 months of follow-up and analyses were restricted to these participants and their matched controls. The mean age was $70(\mathrm{sd}=11.4)$ in the two cohorts (Table 2). The follow-up in the bisphosphonate and control cohorts was similar (mean 4.5 and 4.4 years and maximum 12.9 and 12.9, respectively). All of the bisphosphonate cohort and $9 \%$ of the control cohort received at least one prescription for oral bisphosphonates during the follow-up period. Mean BMI was higher in the control cohort than the bisphosphonate cohort $\left(27.1 \mathrm{~kg} / \mathrm{m}^{2}\right.$ versus $25.5 \mathrm{~kg} / \mathrm{m}^{2}$, respectively). A similar proportion of the bisphosphonate and control cohorts were smokers or reported alcohol consumption. HRT, NSAIDs, steroids, and calcium and vitamin D supplements were all more commonly prescribed in the bisphosphonate cohort. The majority of subjects in the bisphosphonate cohort had used nitrogen containing bisphosphonates $(87 \%)$ or alendronate (70\%).

\section{Overall cancer incidence}

Table 3 contains a comparison of cancer incidence in the bisphosphonate and control cohorts. Overall, in the bisphosphonate cohort compared with the control cohort, there was a reduction in the risk of all cancer after any usage $(\mathrm{HR}=0.87,95 \% \mathrm{CI} 0.82,0.92)$ and after one year of prescriptions ( $\mathrm{HR}=0.87,95 \%$ CI $0.80,0.95)$. Adjustments for potential confounders had little impact on these associations. There were no substantial differences in cancer risk when the analyses were restricted to users of nitrogen containing bisphosphonates or alendronate (data not shown).

\section{Cancer incidence by site}

There was little evidence of a difference in the risk of most site-specific cancers in the bisphosphonate cohort compared with the control cohort (Table 3). There was evidence of reductions in breast and colorectal cancer risk in the bisphosphonate cohort after any usage (adjusted $\mathrm{HR}=0.75,95 \% \mathrm{CI} 0.63,0.89 ; \mathrm{P}=<0.001$ and adjusted $\mathrm{HR}=0.74,95 \% \mathrm{CI} 0.60$, $0.91 ; \mathrm{P}=0.01$, respectively) and after one year of prescriptions (adjusted $\mathrm{HR}=0.79,95 \% \mathrm{CI}$ $0.62,1.01 ; \mathrm{P}=0.06$ and adjusted $\mathrm{HR}=0.72,95 \% \mathrm{CI} 0.53,0.98 ; \mathrm{P}=0.04$, respectively). Further analysis of these cancers is shown below. There was some evidence, though not significant, of an increase in the risk of myeloma (adjusted HR=1.76, 95\% CI 0.91, 3.37; $\mathrm{P}=0.09$ ), and decreases in the risk of endometrial (adjusted $\mathrm{HR}=0.55,95 \% \mathrm{CI} 0.28,1.10$; $\mathrm{P}=0.09$ ), prostate (adjusted $\mathrm{HR}=0.68,95 \% \mathrm{CI} 0.41,1.13 ; \mathrm{P}=0.14$ ) and bladder cancer (adjusted HR=0.67, 95\% CI 0.41, 1.10; $\mathrm{P}=0.11$ ). However, these estimates were based on 
small numbers of incident events $(27,19,50$ and 41 in the bisphosphonate cohort, respectively) and further reliable analysis was not possible

\section{Breast cancer incidence}

Survival curves (Figure 1) indicate that the difference in breast cancer risk in the bisphosphonate and control cohorts seems to attenuate slightly over time. This is also indicated by evidence $(\mathrm{P}=0.01)$ of an interaction between the effect of bisphosphonate usage and time in the proportional hazards model. Dose-response analysis (Table 4) also demonstrated that the association between bisphosphonates and breast cancer risk was less apparent after 3 years $(\mathrm{HR}=0.81,95 \%$ CI $0.57,1.16 ; \mathrm{P}=0.25)$ and after 4 years of bisphosphonate prescriptions ( $\mathrm{HR}=0.94,95 \% \mathrm{CI} 0.57,1.54 ; \mathrm{P}=0.79)$. Subgroup analysis were conducted by identifying members of the control cohort with a diagnosis for osteoporosis/osteopenia or fracture prior to the index date and comparing the risk of breast cancer in these participants to their matched bisphosphonate users (i.e. retaining the matching). In these analyses the association between bisphosphonate usage and breast cancer were attenuated in analyses defined by osteoporosis/osteopenia codes $(\mathrm{HR}=0.90$, $95 \%$ CI $0.52,1.57 ; \mathrm{P}=0.72)$ and fracture codes (HR=0.91, 95\% CI 0.54, 1.52; $\mathrm{P}=0.71)$. Subgroup analyses were also conducted that included any member of either cohort with a diagnosis for osteoporosislosteopenia or fracture (ignoring the matching). In these analyses, the associations between bisphosphonate usage and breast cancer remained $(\mathrm{HR}=0.70,95 \%$ CI 0.46, 1.06; $\mathrm{P}=0.09$ and $\mathrm{HR}=0.56,95 \%$ CI $0.36,0.87 ; \mathrm{P}=0.01$, respectively). The breast cancer association was similar in different BMI categories.

\section{Colorectal Cancer Incidence}

Survival curves (Figure 1) indicate that the difference in colorectal cancer risk in the bisphosphonate and control cohorts seems to increase slightly over time but there was no interaction between the effect of bisphosphonate usage and time $(\mathrm{P}=0.17)$ in the proportional hazards model. Table 4 demonstrates that the association between bisphosphonate usage and colorectal cancer risk was more marked with increasing duration of exposure; after 3 years $(\mathrm{HR}=0.65,95 \% \mathrm{CI} 0.39,1.08 ; \mathrm{P}=0.10)$ and after 4 years of prescriptions $(\mathrm{HR}=0.48,95 \% \mathrm{CI}$ $0.22,1.01 ; \mathrm{P}=0.05$ ). The association was similar in males (after one year of prescriptions HR $0.78,95 \%$ CI $0.47,1.28$ ) and females (after one year of prescriptions HR $0.74,95 \%$ CI 0.56 , 0.97). Subgroup analyses (retaining the matching) indicated that the association between bisphosphonate usage and colorectal cancer was attenuated in controls with osteoporosis/ osteopenia codes and their matched bisphosphonate users (HR=1.18, 95\% CI 0.60, 2.33; $\mathrm{P}=0.63)$ and controls with fracture codes and their matched bisphosphonate users $(\mathrm{HR}=0.95$, $95 \%$ CI $0.45,2.00 ; \mathrm{P}=0.90$ ), but these estimates were based on small numbers. In subgroup analyses (ignoring the matching) there was some attenuation of the association between bisphosphonate usage and colorectal cancer in participants with an osteoporosis/osteopenia diagnosis $(\mathrm{HR}=0.82,95 \%$ CI $0.48,1.40 ; \mathrm{P}=0.46)$ and more marked attenuation in participants with a fracture diagnosis $(\mathrm{HR}=1.05,95 \% \mathrm{CI} 0.58,1.89 ; \mathrm{P}=0.87)$. The association appeared similar in different BMI categories.

\section{Discussion}

This cohort study of mainly elderly women found a reduction in overall cancer risk in bisphosphonate users. There was little evidence of an increase in any site-specific cancers in the bisphosphonate users. There was evidence of $20 \%$ and $25 \%$ reductions in breast cancer and colorectal cancer risk in bisphosponate users, respectively. The observed reduction in breast cancer risk was attenuated with increasing use of bisphosphonates, unlike for colorectal cancer where stronger associations were seen with increasing use. In subgroup analyses where members of the unexposed cohort with a history of osteoporosis/osteopenia 
or a fracture were compared to their matched control the associations for breast and colorectal cancer were attenuated.

The association between bisphosphonate use and all cancer risk or cancer risk by site has not been examined, with the exception of breast,(14-16) colorectal $(17 ; 18)$ and esophageal cancer. $(17 ; 19)$ Importantly, we observed no increase in cancers overall or site specific cancers. The magnitude of the reduction in breast cancer risk we observed was similar to three previous studies.(14-16) However, two of these studies were breast cancer casecontrol studies $(14 ; 15)$ and have various weaknesses including low response rates, $(14 ; 15)$ differential response rates between cases and controls (15) and potential for recall bias related to bisphosphonate exposure.(14) Interestingly, the only previous cohort study(16) demonstrated a reduction in breast cancer risk after less than 2 years of bisphosphonate usage but not after longer usage, which is similar to the attenuation of the breast cancer association with increasing usage that we observed.

There is substantial preclinical evidence indicating that bisphosphonates may reduce cancer risk $(4 ; 6 ; 26 ; 27)$ and trials of clodronate $(8)$ and, particularly, zoledronate (11-13) in breast cancer patients demonstrate that bisphosphosphonates positively influence cancer outcomes that are unrelated to skeletal metastases. Although these studies address cancer progression, they provide support for bisphosphonate related anti-breast cancer activity and suggest that the reduction in breast cancer risk we observed may be real. An alternative explanation is that the estimate of breast cancer risk is confounded by cumulative oestrogen exposure or other factors that influence both bone density and cancer risk. Previous studies of postmenopausal women have confirmed that higher bone mineral density is associated with increased breast cancer risk (28-30). The pattern of reduction in the incidence of oestrogen related cancers (breast and endometrial) in our study, together with attenuation of the breast cancer association with increasing use of bisphosphonates, and when the matched analysis was restricted to subjects who were similar in terms of history of osteoporosis/osteopenia or fracture, suggests that confounding by indication may underlie the reductions in breast cancer incidence we observed. However, in subgroup analyses where matching was not retained the reductions in breast cancer incidence remained, although the subjects included in the unexposed and exposed cohorts in this analysis may be less comparable than in the analysis that retained the matching.

This is the first cohort study to observe a reduction in colorectal cancer risk in bisphosphonate users and we show that the association was more marked with increasing bisphosphonate use, although it was attenuated in subjects with a history of oesteoporosis/ osteopenia or fracture. A recent case-control study,(17) also within the UKGPRD showed a $13 \%$ reduction colorectal cancer risk in individuals with one or more prescriptions for bisphosphonates. Also a $33 \%$ reduction in risk with three or more prescriptions for bisphosphonates has also recently been described in a case-control study from Israel.(18) Confounding by low bone density may be less of a problem in our colorectal analyses because, colorectal cancer is not generally considered to be a hormone related malignancy to the same extent as breast cancer (31) and high bone density has been associated with reduced rather than increased colorectal cancer risk.(32-34) Our estimate of the association between bisphosphonate use and colorectal cancer risk may remain confounded by body mass, alcohol and smoking, as data on these parameters were substantially incomplete. Data on physical activity was also too incomplete to use. Our results provide only qualified support for a protective effect of bisphosphonate use against colorectal cancer development and further investigations are required.

This study has some strengths and limitations. Strengths include the large size, reasonable period of follow-up, exclusion of prior cancers, and the use of recorded prescription data. 
Underestimation of bisphosphonate usage is unlikely, because these drugs cannot be obtained without prescription in the UK but overestimation of usage is possible, as compliance with bisphosphonate prescribing is suboptimal.(35) A further weakness was the ascertainment of cancer incidence as linkage to cancer registries was not available, although the recording of cancer outcomes within the GPRD has been shown to be high,(20) and it is reassuring that the incidences of most cancers in the control cohort were similar to population rates for England. Although it is possible that early cancer symptoms could lead to an increased likelihood of bisphosphonate prescriptions, particularly for cancer symptoms related to weight loss and low bone mineral density, this would lead to an increased cancer risk in the bisphosphonate cohort and could not explain our findings for either breast or colorectal cancer. Other limitations include the relatively high proportion of missing data on potential confounders such as weight, potential for residual confounding and multiple comparisons.

In conclusion, this analysis of a large population based sample of bisphosphonate users and matched controls showed a decrease in breast and colorectal cancer risk. There was also some evidence of decreases in bladder, endometrial and prostate cancer risk. Further studies are required to examine the relationship between use of bisphosphonates and cancer incidence but it is reassuring that cancer risk was not increased in users of these drugs.

\section{Acknowledgments}

We thank Maciej Domanski, MSc (Centre for Public Health, Queen's University Belfast, Belfast, United Kingdom) for data management. This study is based in part on data from the Full Feature General Practice Research Database obtained under licence from the UK Medicines and Healthcare Products Regulatory Agency. However, the interpretation and conclusions contained in this study are those of the authors alone. Access to the GPRD database was funded through the Medical Research Council's licence agreement with MHRA.

\section{References}

1. Udell JA, Fischer MA, Brookhart MA, Solomon DH, Choudhry NK. Effect of the Women's Health Initiative on osteoporosis therapy and expenditure in Medicaid. J Bone Miner Res. 2006; 21:765771. [PubMed: 16734392]

2. Usher C, Teeling M, Bennett K, Feely J. Effect of clinical trial publicity on HRT prescribing in Ireland. Eur J Clin Pharmacol. 2006; 62:307-310. [PubMed: 16432715]

3. Watson J, Wise L, Green J. Prescribing of hormone therapy for menopause, tibolone, and bisphosphonates in women in the UK between 1991 and 2005. Eur J Clin Pharmacol. 2007; 63:843849. [PubMed: 17598097]

4. Giraudo E, Inoue M, Hanahan D. An amino-bisphosphonate targets MMP-9-expressing macrophages and angiogenesis to impair cervical carcinogenesis. J Clin Invest. 2004; 114:623-633. [PubMed: 15343380]

5. Peyruchaud O, Winding B, Pecheur I, Serre CM, Delmas P, Clezardin P. Early detection of bone metastases in a murine model using fluorescent human breast cancer cells: application to the use of the bisphosphonate zoledronic acid in the treatment of osteolytic lesions. J Bone Miner Res. 2001; 16:2027-2034. [PubMed: 11697798]

6. Senaratne SG, Pirianov G, Mansi JL, Arnett TR, Colston KW. Bisphosphonates induce apoptosis in human breast cancer cell lines. Br J Cancer. 2000; 82:1459-1468. [PubMed: 10780527]

7. Kavanagh KL, Guo K, Dunford JE, Wu X, Knapp S, Ebetino FH, Rogers MJ, Russell RG, Oppermann U. The molecular mechanism of nitrogen-containing bisphosphonates as antiosteoporosis drugs. Proc Natl Acad Sci USA. 2006; 103:7829-7834. [PubMed: 16684881]

8. Diel IJ, Solomayer EF, Costa SD, Gollan C, Goerner R, Wallwiener D, Kaufmann M, Bastert G. Reduction in new metastases in breast cancer with adjuvant clodronate treatment. N Engl J Med. 1998; 339:357-363. [PubMed: 9691101]

9. Powles T, Paterson A, McCloskey E, Schein P, Scheffler B, Tidy A, Ashley S, Smith I, Ottestad L, Kanis J. Reduction in bone relapse and improved survival with oral clodronate for adjuvant 
treatment of operable breast cancer [ISRCTN83688026]. Breast Cancer Res. 2006; 8:R13. [PubMed: 16542503]

10. Saarto T, Vehmanen L, Virkkunen P, Blomqvist C. Ten-year follow-up of a randomized controlled trial of adjuvant clodronate treatment in node-positive breast cancer patients. Acta Oncol. 2004; 43:650-656. [PubMed: 15545185]

11. Gnant M, Mlineritsch B, Luschin-Ebengreuth G, Kainberger F, Kassmann H, Piswanger-Solkner JC, Seifert M, Ploner F, Menzel C, Dubsky P, Fitzal F, Bjelic-Radisic V, et al. Adjuvant endocrine therapy plus zoledronic acid in premenopausal women with early-stage breast cancer: 5-year follow-up of the ABCSG-12 bone-mineral density substudy. Lancet Oncol. 2008; 9:840-849. [PubMed: 18718815]

12. Brufsky AM, Bosserman LD, Caradonna RR, Haley BB, Jones CM, Moore HC, Jin L, Warsi GM, Ericson SG, Perez EA. Zoledronic acid effectively prevents aromatase inhibitor-associated bone loss in postmenopausal women with early breast cancer receiving adjuvant letrozole: Z-FAST study 36-month follow-up results. Clin Breast Cancer. 2009; 9:77-85. [PubMed: 19433387]

13. Eidtmann H, de Boer R, Bundred N, Llombart-Cussac A, Davidson N, Neven P, von Minckwitz G, Miller J, Schenk N, Coleman R. Efficacy of zoledronic acid in postmenopausal women with early breast cancer receiving adjuvant letrozole: 36-month results of the ZO-FAST Study. Ann Oncol. 2010; 21:2188-2194. [PubMed: 20444845]

14. Newcomb PA, Trentham-Dietz A, Hampton JM. Bisphosphonates for osteoporosis treatment are associated with reduced breast cancer risk. Br J Cancer. 2010; 102:799-802. [PubMed: 20160722]

15. Rennert G, Pinchev M, Rennert HS. Use of bisphosphonates and risk of postmenopausal breast cancer. J Clin Oncol. 2010; 28:3577-3581. [PubMed: 20567021]

16. Chlebowski RT, Chen Z, Cauley JA, Anderson G, Rodabough RJ, McTiernan A, Lane DS, Manson JE, Snetselaar L, Yasmeen S, O’Sullivan MJ, Safford M. Oral bisphosphonate use and breast cancer incidence in postmenopausal women. J Clin Oncol. 2010; 28:3582-3590. [PubMed: 20567009]

17. Green J, Czanner G, Reeves G, Watson J, Wise L, Beral V. Oral bisphosphonates and risk of cancer of oesophagus, stomach, and colorectum: case-control analysis within a UK primary care cohort. BMJ. 2010; 341:c4444. [PubMed: 20813820]

18. Rennert G, Pinchev M, Rennert HS, Gruber SB. Use of bisphosphonates and reduced risk of colorectal cancer. J Clin Oncol. 2011; 29:1146-1150. [PubMed: 21321296]

19. Cardwell CR, Abnet CC, Cantwell MM, Murray LJ. Exposure to oral bisphosphonates and risk of esophageal cancer. JAMA. 2010; 304:657-663. [PubMed: 20699457]

20. Jick H, Jick SS, Derby LE. Validation of information recorded on general practitioner based computerised data resource in the United Kingdom. BMJ. 1991; 302:766-768. [PubMed: 2021768]

21. Takkouche B, Regueira-Mendez C, Etminan M. Breast cancer and use of nonsteroidal antiinflammatory drugs: a meta-analysis. J Natl Cancer Inst. 2008; 100:1439-1447. [PubMed: 18840819]

22. Rothwell PM, Wilson M, Elwin CE, Norrving B, Algra A, Warlow CP, Meade TW. Long-term effect of aspirin on colorectal cancer incidence and mortality: 20-year follow-up of five randomised trials. Lancet. 2010; 376:1741-1750. [PubMed: 20970847]

23. Chlebowski RT, Johnson KC, Kooperberg C, Pettinger M, Wactawski-Wende J, Rohan T, Rossouw J, Lane D, O’Sullivan MJ, Yasmeen S, Hiatt RA, Shikany JM, et al. Calcium plus vitamin D supplementation and the risk of breast cancer. J Natl Cancer Inst. 2008; 100:1581-1591. [PubMed: 19001601]

24. Wactawski-Wende J, Kotchen JM, Anderson GL, Assaf AR, Brunner RL, O’Sullivan MJ, Margolis KL, Ockene JK, Phillips L, Pottern L, Prentice RL, Robbins J, et al. Calcium plus vitamin D supplementation and the risk of colorectal cancer. N Engl J Med. 2006; 354:684-696. [PubMed: 16481636]

25. Psaty BM, Siscovick DS. Minimizing bias due to confounding by indication in comparative effectiveness research: the importance of restriction. JAMA. 2010; 304:897-898. [PubMed: 20736474] 
26. Coxon JP, Oades GM, Kirby RS, Colston KW. Zoledronic acid induces apoptosis and inhibits adhesion to mineralized matrix in prostate cancer cells via inhibition of protein prenylation. BJU Int. 2004; 94:164-170. [PubMed: 15217454]

27. Guise TA. Antitumor effects of bisphosphonates: promising preclinical evidence. Cancer Treat Rev. 2008; 34 (Suppl 1):S19-S24. [PubMed: 18486348]

28. Chen Z, Arendell L, Aickin M, Cauley J, Lewis CE, Chlebowski R. Hip bone density predicts breast cancer risk independently of Gail score: results from the Women's Health Initiative. Cancer. 2008; 113:907-915. [PubMed: 18666209]

29. Zhang Y, Kiel DP, Kreger BE, Cupples LA, Ellison RC, Dorgan JF, Schatzkin A, Levy D, Felson DT. Bone mass and the risk of breast cancer among postmenopausal women. N Engl J Med. 1997; 336:611-617. [PubMed: 9032046]

30. Zmuda JM, Cauley JA, Ljung BM, Bauer DC, Cummings SR, Kuller LH. Bone mass and breast cancer risk in older women: differences by stage at diagnosis. J Natl Cancer Inst. 2001; 93:930936. [PubMed: 11416114]

31. Lin JH, Giovannucci E. Sex hormones and colorectal cancer: what have we learned so far? J Natl Cancer Inst. 2010; 102:1746-1747. [PubMed: 21068431]

32. Ganry O, Lapotre-Ledoux B, Fardellone P, Dubreuil A. Bone mass density, subsequent risk of colon cancer and survival in postmenopausal women. Eur J Epidemiol. 2008; 23:467-473. [PubMed: 18470627]

33. Zhang Y, Felson DT, Ellison RC, Kreger BE, Schatzkin A, Dorgan JF, Cupples LA, Levy D, Kiel DP. Bone mass and the risk of colon cancer among postmenopausal women: the Framingham study. Am J Epidemiol. 2001; 153:31-37. [PubMed: 11159144]

34. Nelson RL, Turyk M, Kim J, Persky V. Bone mineral density and the subsequent risk of cancer in the NHANES I follow-up cohort. BMC Cancer. 2002; 2:22. [PubMed: 12377099]

35. Cramer JA, Gold DT, Silverman SL, Lewiecki EM. A systematic review of persistence and compliance with bisphosphonates for osteoporosis. Osteoporos Int. 2007; 18:1023-1031. [PubMed: 17308956] 


\section{Novelty and impact statements}

The use of oral bisphosphonates has increased dramatically but although a few studies been investigated cancer risks at specified sites (breast, colorectal and gastrooesophageal) little is known about the risks of other cancers or overall cancer burden associated with these drugs. Our large cohort study demonstrates $25 \%$ reductions in the risk of breast and colorectal cancer in bisphosphonate users and importantly shows no increase in cancer risk at any site in bisphosphonate users. 


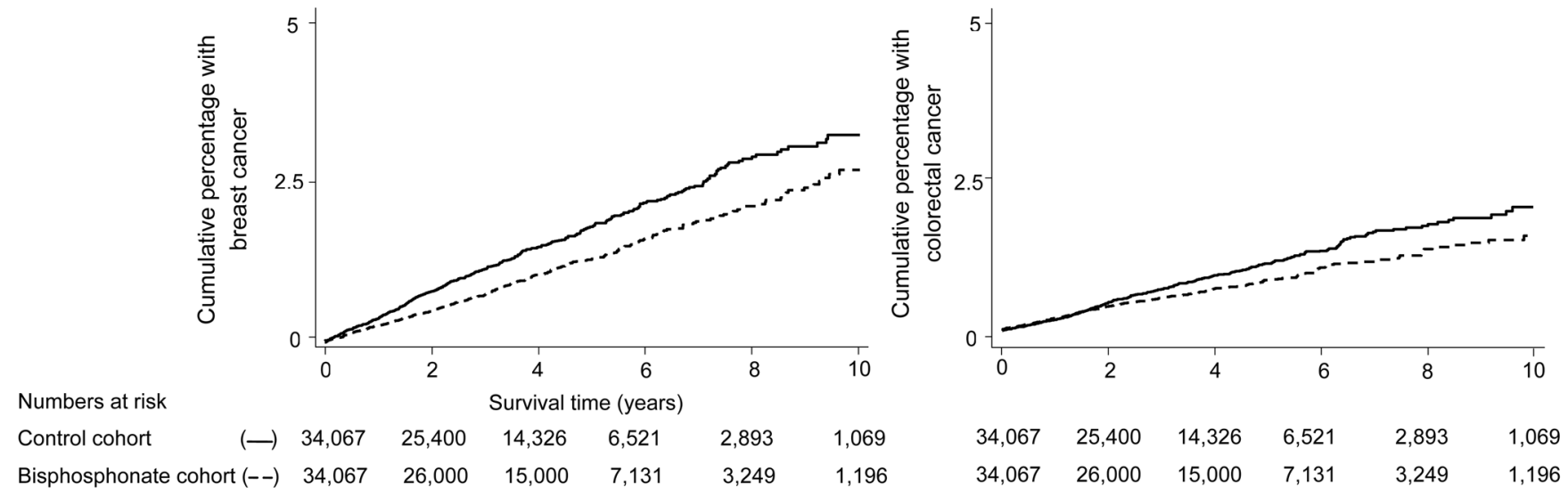

Figure 1.

Time to breast and colorectal cancer in the bisphosphonate and control cohort. 
Table 1

Cancer ascertainment in the control cohort $(n=46,036)$.

\begin{tabular}{lccc}
\hline Site & Observed cases & Expected cases $^{a}$ & Standardised Incidence Ratio (95\% CI) \\
\hline Males and Females & & & \\
All cancers $b$ & 3,126 & 2866.35 & $1.09(1.05,1.13)$ \\
Lung cancer & 382 & 401.21 & $0.95(0.86,1.14)$ \\
Colorectal cancer & 414 & 397.07 & $1.04(0.94,1.15)$ \\
Lymphoma or leukemia & 180 & 169.3 & $1.06(0.91,1.23)$ \\
Gastro-esophageal & 149 & 159.53 & $0.93(0.79,1.10)$ \\
Malignant melanoma & 101 & 68.81 & $1.47(1.20,1.78)$ \\
Bladder cancer & 146 & 100.64 & $1.45(1.23,1.71)$ \\
Pancreas cancer & 71 & 94.60 & $0.75(0.59,0.95)$ \\
Myeloma & 60 & 44 & $1.37(1.04,1.76)$ \\
Females only & & & $1.05(0.97,1.14)$ \\
Breast cancer & 588 & 560.54 & $0.92(0.73,1.14)$ \\
Ovary & 85 & 92.45 & $0.80(0.63,1.01)$ \\
Endometrial & 73 & 91.07 & $1.00(0.86,1.15)$ \\
Males only & & & \\
Prostate cancer & 188 & 188.83 & \\
\hline
\end{tabular}

${ }^{a}$ Expected number of cases in the control cohort by age and sex distribution based upon incidence rates from England in 2005.

$b_{\text {Excludes non-melanoma skin cancer. }}$ 
Table 2

Participant characteristics in bisphosphonate cohort and matched control cohort including only individuals with more than 6 months follow-up.

\begin{tabular}{|c|c|c|c|c|}
\hline \multirow[t]{2}{*}{ Characteristic } & \multicolumn{2}{|c|}{ Bisphosphonate cohort } & \multicolumn{2}{|c|}{ Matched control cohort } \\
\hline & n $(\%)$ & Mean (sd) & $\%(\mathbf{n})$ & Mean (sd) \\
\hline Age (at index date) & $41,826(100 \%)$ & $70.0(11.4)$ & $41,826(100 \%)$ & $70.0(11.4)$ \\
\hline 40 to 49.9 & $2,057(5 \%)$ & & $2,057(5 \%)$ & \\
\hline 50 to 59.9 & $6,600(16 \%)$ & & $6,600(16 \%)$ & \\
\hline 60 to 69.9 & $10,772(26 \%)$ & & $10,772(26 \%)$ & \\
\hline 70 to 79.9 & $13,753(33 \%)$ & & $13,753(33 \%)$ & \\
\hline 80 to 89.9 & $7,715(18 \%)$ & & $7,715(18 \%)$ & \\
\hline 90 or greater & $894(2 \%)$ & & $894(2 \%)$ & \\
\hline \multicolumn{5}{|l|}{ Sex } \\
\hline Male & $7,777(19 \%)$ & & $7,777(19 \%)$ & \\
\hline Female & $34,049(81 \%)$ & & $34,049(81 \%)$ & \\
\hline Any bisphosphonate prescription (during follow-up period) & $41,826(100 \%)$ & & $3,705(9 \%)$ & \\
\hline Bisphosphonate in DDDs per day (during follow-up period) & 41,826 & $0.59(0.49)$ & 41,826 & $0.03(0.16)$ \\
\hline Follow-up (years) & $41,826(100 \%)$ & $4.5(2.6)$ & $41,826(100 \%)$ & $4.4(2.6)$ \\
\hline BMI & $20,199(48 \%)$ & $25.5(2.25)$ & $17,513(42 \%)$ & $27.1(2.25)$ \\
\hline Missing & $21,627(52 \%)$ & & $24,313(58 \%)$ & \\
\hline \multicolumn{5}{|l|}{ Smoking } \\
\hline Never & $12,609(30 \%)$ & & $11,871(28 \%)$ & \\
\hline Ex & $6,916(17 \%)$ & & $5,689(14 \%)$ & \\
\hline Current & $4,328(10 \%)$ & & $3,531(8 \%)$ & \\
\hline Missing & $17,973(43 \%)$ & & $20,735(50 \%)$ & \\
\hline \multicolumn{5}{|l|}{ Alcohol } \\
\hline Never & $3,619(9 \%)$ & & $3,178(8 \%)$ & \\
\hline Ex & $534(1 \%)$ & & $369(1 \%)$ & \\
\hline Current & $11,146(27 \%)$ & & $10,406(25 \%)$ & \\
\hline Missing & $26,527(63 \%)$ & & $27,873(67 \%)$ & \\
\hline HRT prescription, in females ( $\geq 5$ prescriptions, in 3 years before index date) & $4,513(13 \%)$ & & $3,167(9 \%)$ & \\
\hline NSAID prescription ( $\geq 10$ prescriptions, in 3 years before index date) & $11,319(27 \%)$ & & $8,989(21 \%)$ & \\
\hline Steroid prescription ( 25 prescriptions, in 3 years before index date) & $9,085(22 \%)$ & & $1,170(3 \%)$ & \\
\hline Vitamin D supplementation ( $\geq 1$ prescription, in 6 months after index date) & $14,919(36 \%)$ & & $1,490(4 \%)$ & \\
\hline Calcium supplementation ( $\geq 1$ prescription, in 6 months after index date) & $23,493(56 \%)$ & & $1,905(5 \%)$ & \\
\hline
\end{tabular}




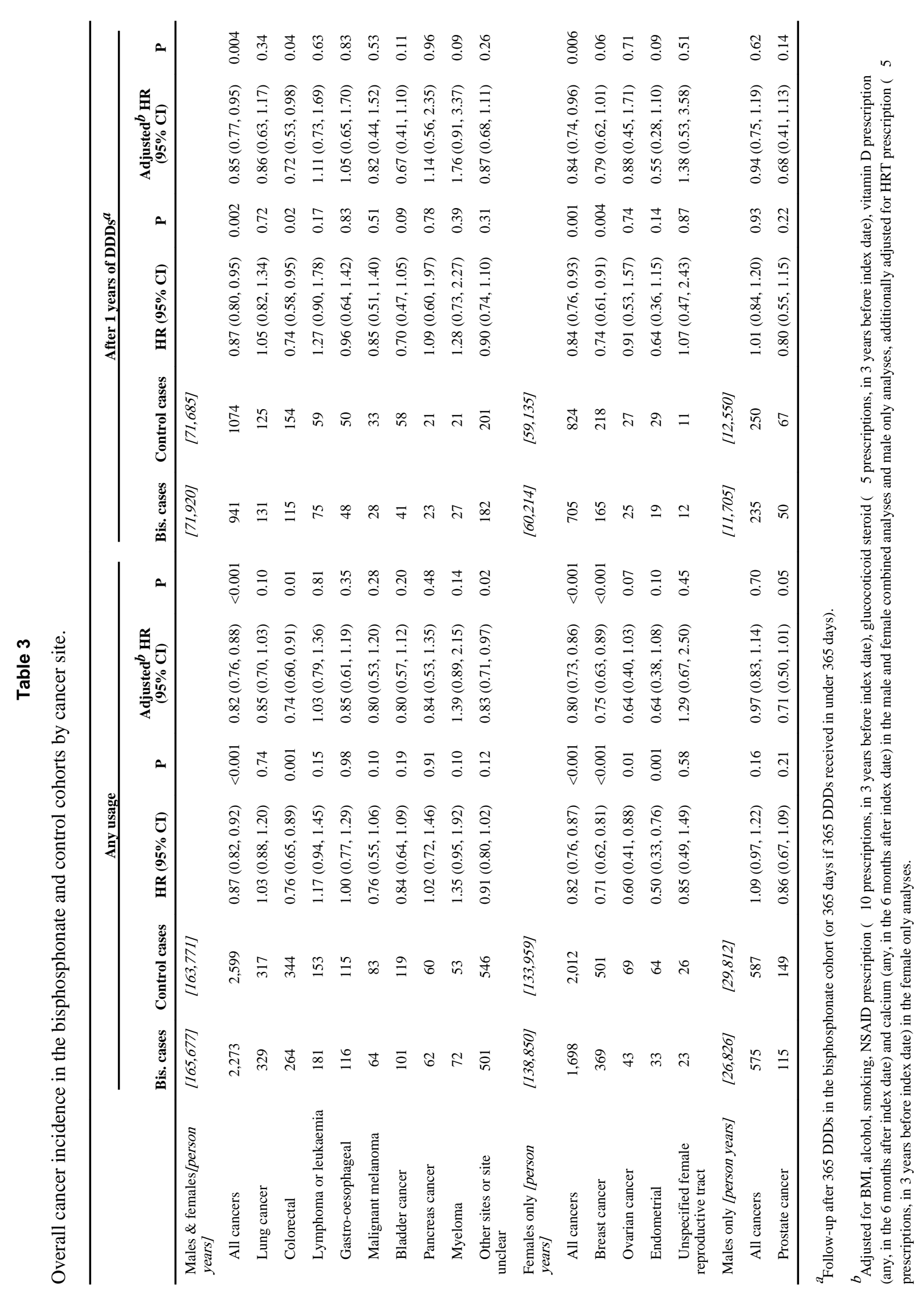

Int J Cancer. Author manuscript; available in PMC 2013 September 01. 


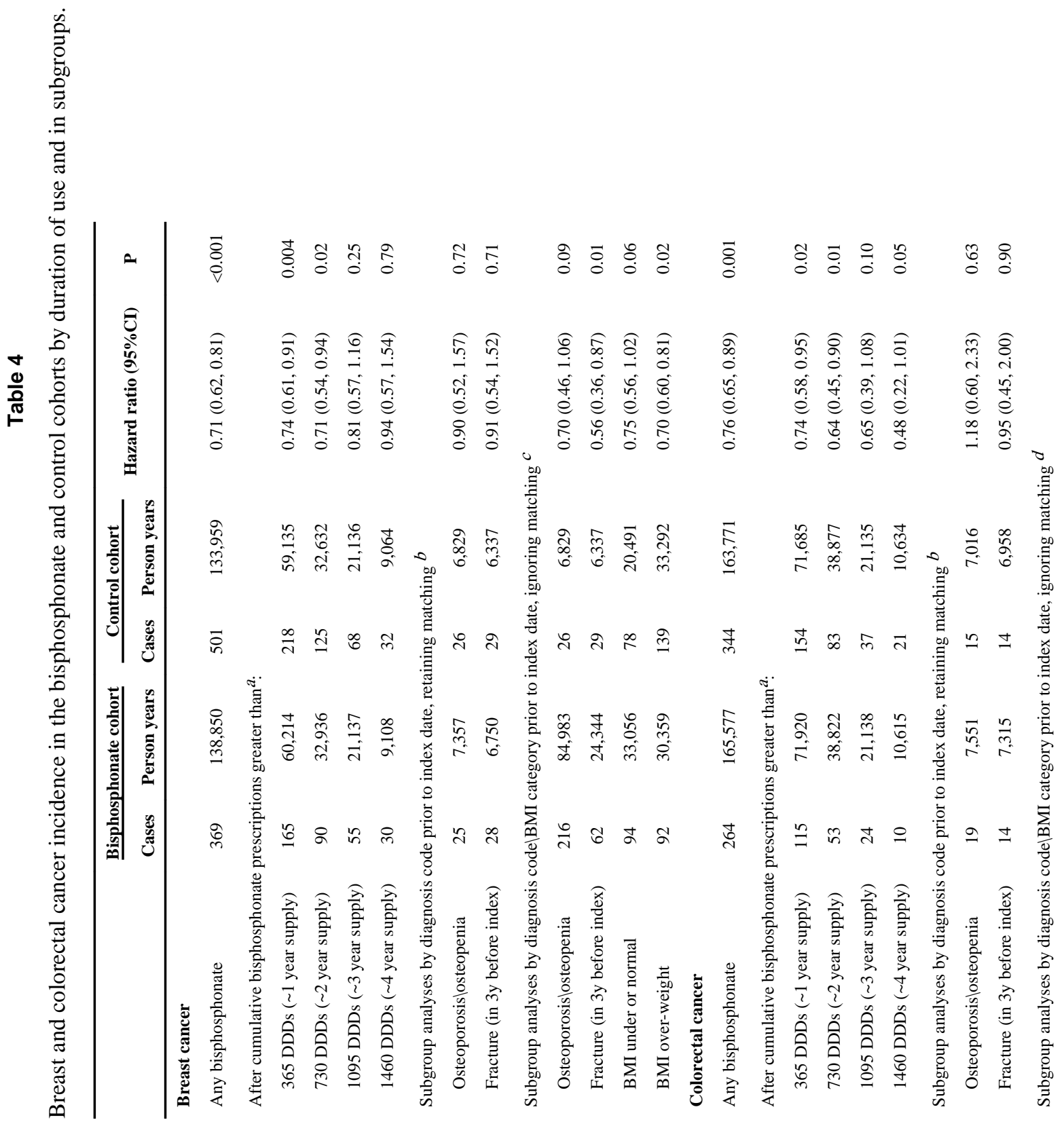




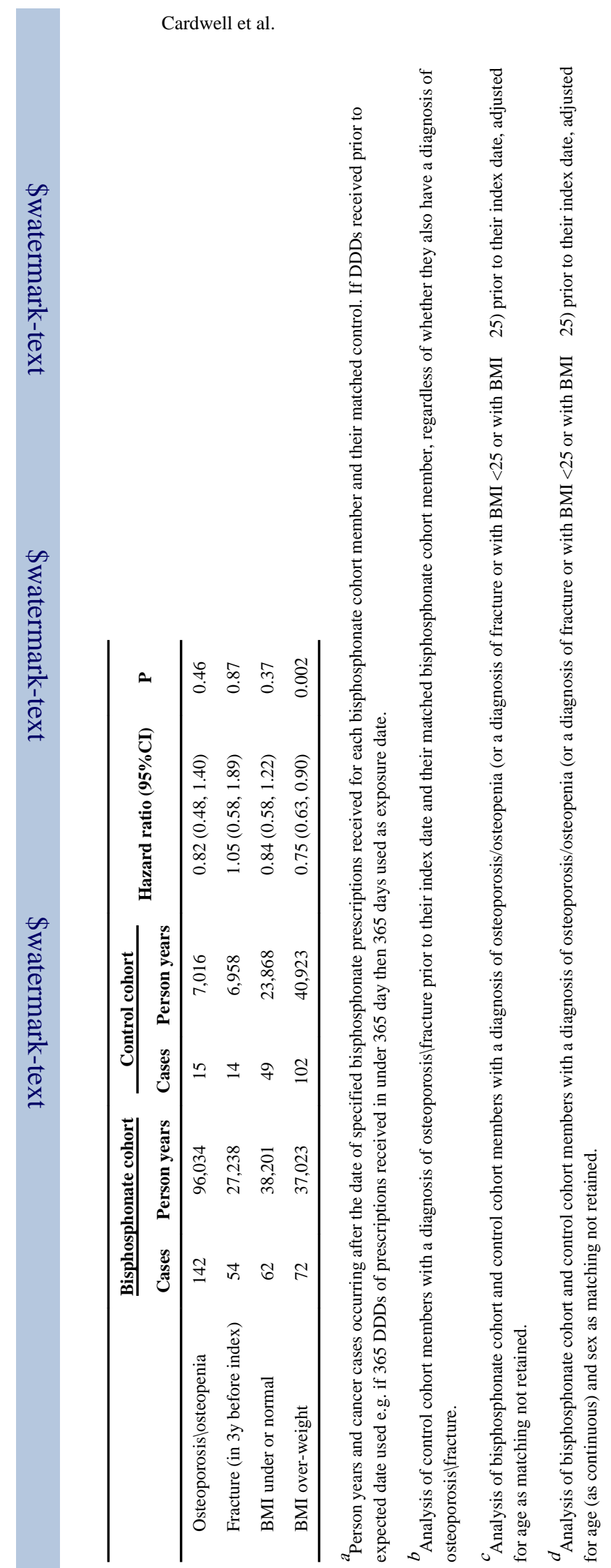

Int J Cancer. Author manuscript; available in PMC 2013 September 01. 